\title{
Examining the Impact of Using Social Networks on Political Knowledge and Political Attitude by Iranian University Students
}

\author{
ABDOLREZA ALAMI \\ HAMEDI MOHD ADNAN \\ Universiti Malaya \\ SEDIGHEH SHAKIB KOTAMJANI \\ Universiti Putra Malaysia
}

\begin{abstract}
Social Network Sites (SNSs) play key role to raise individuals' awareness in terms of political issues around the world. Young generation particularly university students utilize social networks for political activism and discussion. The present study investigates the effect of social network on political knowledge and attitude of Iranian university students. Mixed- method design was employed to collect quantitative data through a questionnaire followed by an emailed interview with Iranian media experts. The sample size in the study consisted of 382 Iranian students and 12 media experts. The findings of the current study showed that there is generally a direct and positive relation between the level of use of social networks and political knowledge, and attitude. Moreover, the results revealed that using social network sites have a significant positive effect on student's level of political knowledge and political knowledge mediates the positive effect of social network use by Iranian university students on their political behavior. The results of interview corroborate that easy access to modern information sources has increased political knowledge of the students. The results also implied the necessity of deploying an intelligent filtering rather than indiscriminate blocking of the social network websites.
\end{abstract}

Keywords: Social network site, political knowledge, political attitude, political behavior, Iranian university students.

\section{INTRODUCTION}

The relationship between Internet and politics has been under unprecedented number of academic studies during the last decade (Zhang et al., 2009). One of the key features of the Internet is the availability of Social Network Sites (SNSs). SNSs are online communities where users connect to the people within their social circle or beyond it. The variety of services available in SNSs and their widespread and increasing influence as an information source and their position in the people's contact has increased the number of researches on the behavior of people in the social network sites (Brundidge, 2010a).

The popularity of social network sites attracted mostly adolescents and young adults compared to others all over the world (McLeod et al., 1999a). The number of active adult users in the online networking sites such as popular social portals like Facebook has quadrupled between 2005 and 2008 which is an increase from 8\% to 35\% (Huckfeldt et al., 1995). 
Currently, social media have become an inseparable part of Iranian' everyday lives for different functions; i.e. education and political engagement. Globally, young generation use the social networking to contribute in the government general public policies and engage in the political mobilization. For instance, Zhang et al. (2009) found that the recent changes and revolutions in the Middle East, which affected Iran, Egypt, Tunisia, Syria, Lebanon and Libya, happened under the influence of social networking on these governments' policies. The emergence of Facebook prior to the highly disputed presidential elections in Iran allowed the opposition to use this platform to voice out their concern over allegations that the polling stations were rigged and that the election should have been nullified. It was the first time that political movements and social media were bonded and it sparked massive protests across the country.

The Iranian government operates one of the largest and most sophisticated Internet censorship regimes in the world (Calhoun, 1988). As a result, youths are of top importance in active electronic participation in Iran because of their proportion in Internet users. Recent work has determined that Facebook use that is explicitly political (supporting a candidate, creating a political event, etc.) predicts political behaviors and political engagement among young people, but that kind of behavior is limited to a small sector of the population (Kenski et al., 2006). However, in Iran, as a country where internet filtering is used vastly, it is necessary to study political behaviors among the young adults.

This study aims to fill the gap in the existing literature and investigate the effects of SNSs and their services on the political attitude and political knowledge of Iranian students (Sweetser et al., 2008a; Valenzuela et al., 2009a). Nevertheless, in Iran, while the government applies Internet filtering, the effect of SNSs usage on young adults' political knowledge and attitudes is not clear. While many believe that the rise of SNSs have increased the political and social interaction, little is still known about the factors that promote the use of them in the political context. It is a long time that mass media has been found to have a socializing influence. For example, it is apparent that media usage has a role in the formation of political knowledge and opinions among the adult group (Sotirovic et al., 2001) and it serves as a medium for the participation especially in the young generation (Shah et al., 2007). Therefore, the following research questions were formulated:

RQ1: Does political knowledge mediate the relationship between social network use by Iranian university students and political behavior?

RQ2: Does political attitude mediate the relationship between social network use by Iranian university students and political behavior?

\section{Political Knowledge and Social Network Sites}

It is necessary to define 'political knowledge'. The term civic and political knowledge are used interchangeably. According to Maiello, Oser and Biedermann (2003), knowledge of politics and political institutes is called civic knowledge, a form of knowledge that has some positive functions such as promoting political participation as well as enhancing support for democratic and civic values. It also helps citizens to better understand the current affairs shaping their 
societies (Galston, 2004). There is no specific definition of civic knowledge; but, the term generally refers to relevant information and the level of skills and understanding of civic and political affairs surrounding regional, national and global issues. A country's democracy relates to its citizens; however, it cannot truly work without informed citizens (Gans, 2003). According to Popkin and Dimock (1999): "Basic political knowledge structures the kinds of inferences that citizens make about the world. The way that citizens reason about politics [and] the kinds of information they use to make political decisions are all affected by their familiarity with the political world" (p. 142).

The above quotation offers a sound definition of political knowledge. It both considers the role of political knowledge for political discussion among citizens and for political decision making. The more civic and political knowledge that people accumulate, the better they can recognize the effect of public policies on their interests. In essence, they are able to promote their interests more efficiently (Galston, 2007). Low civic and political knowledge generates weakly rooted political ideologies, a superficial understanding of public policy, intolerance of minority groups and distrust political institutions (Hart et al., 2004). These functions of civic and political knowledge are very important, but this study aims to examine whether using of social networks has any effect on political knowledge of Iranian university students.

In Sweetser's et al. (2008a) opinion, social networking is a platform and a kind of practice that have features such as community building, collaboration, information sharing and ultimately participation in the decision-making process. Smith et al. (2008) also in a similar way described SNSs as a class of tools and specifically network tools that encourage individuals to learn from each other and together while they can keep their control over identity, presence, space, time, activity and relationship. Social network sites like Facebook are developed for general audience and population while there are other websites that their audience is a particular niche. YouthNoise.org and TakingITGlobal.org are examples of social networks that offer services for the advocates and people interested in social issues like human rights and poverty (Zhang et al., 2009). Moreover, It is found by some researchers that social media has casual effect on the political knowledge and they explain it with "surprise effect" that unexpected political content has an effect on those people who are not interested in politics but by screening the political information the political knowledge of this group of online users is widened (Cantijoch et al., 2008; Sweetser et al., 2008a).

In the survey conducted by Pew Internet and American Life Project, it was found that 40 percent of those users who are using SNSs are engaged in some political activities including registering as a friend to a candidate or getting information in order to discover the political affiliation and interest during 2008 elections (Smith et al., 2008).

Several studies on the motivations for using SNSs have found that social network websites are used primarily for interaction needs (Papacharissi et al., 2008; Postelnicu et al., 2008; Sweetser et al., 2008b). As an example, Postelnicu et al. (2008) found that the people who visited a candidate's profile in Myspace have primarily aimed to connect with other supporters and find what others say about him and at a lowest level, they engaged in the discussions with the candidate. 
Richey (2008b) has studied how political knowledge in social networks influences voters and his research show that social networking sites exert a powerful influence on voters. People with political knowledge are more influential and help the voters with low information to choose the candidates wisely. In his view political knowledge in social network influences the vote choice. Yet, in determining the extent of the influence, his study has not examined the different extent of the knowledge the network members have. Social networks may play a role in the distribution of political information and promoting political change which both certainly depend on the context as a source of ideas, discussions and comments not found in the traditional media.

To find a probable relationship between use of SNSs and political knowledge, Baumgartner et al. (2010b) measured daily or weekly exposures to SNSs and found that there is a significant relationship between exposures to SNSs and political online expression, but not to offline political participation such as voting, signing petitions, or calling a politician. These researchers focus on the frequency and time of SNSs use but not on their effects in practical political activities.

Investigating the relationship between social networks, political knowledge and participating in election campaigns, Dimitrova et al. (2011) found out that digital media use has weak effects on political learning, but remarkable effects on political participation. In an effort to reveal the relationship between Internet use and political knowledge in Spain, Gajora (2011) believes that the rise of online activity leads to political knowledge increase, which promotes the motivation for political participation. Gajora had found a linear relation between online activity and political knowledge.

\section{Political Attitude and Social Network Sites}

Eagly and Chaiken as mentioned in Sweetser et al. (2008a) defined attitude as "a psychological tendency that is expressed by evaluating a particular entity with some degree of favor or disfavor" ( p. 110). This definition focuses on attitude expression and evaluation, which is the most suitable definition for this study. On the other hand, Kiesler et al. (1969) distinguish opinions from attitudes and believe that 'opinions should be defined as an overt expression of a covert attitude' which is used in this study (Smith et al., 2008). political attitudes refers to the attitudes of people about public life covered by political psychology, for instance views on nationalism, political conservatism, political liberalism, political radicalism etc.

Social network sites promote norms of trust and reciprocity among the users by creating the feeling of being connected to others and increasing their knowledge about the others and this eventually can result in motivation for the participation in the political process (Valenzuela et al., 2009b). As an example, in case of Facebook, the existing ties and communities of its users is reinforced by remaining updated about what is going on with their contacts (Cheung et al., 2011; Smock et al., 2011). Such kind of desire for social interaction may lead into "inadvertent encounters" with the political information which is disseminated through social network sites (Ancu et al., 2009).

According to some scholars, using SNSs for social interaction can have a minimum effect on political engagement and participation at least (Zúñiga et al., 2014). In the considerations for the political purposes, SNSs can be a good shelter for those individuals who are marginalized 
and those social groups which were traditionally deprived from the mainstream media and political debate and they could not be exposed or advance their interests (Downey et al., 2003). Vitak et al. (2011) provided some statistical support for this claim and they concluded that "Political activity on Facebook (e.g., posting a politically oriented status update, becoming a 'fan' of a candidate) is a significant predictor of other forms of political participation (e.g., volunteering for an organizing, signing a paper or online petition)" (p. 107).

The big difference between SNSs and other media is in their number of audience that consumes political information. While most of the media have a limited audience, SNSs give an opportunity for the citizens to interject their opinions into the political atmosphere, to reach out and to respond in way not possible before. Hanson et al. (2010) claimed that SNSs encourage citizens to "create their own political content, distribute it online, and comment on the content created by others" (p. 585). A study by Pew prior to 2012 Election Day showed that almost one-fourth of registered voters used SNSs such as Twitter and Facebook to discuss and find their voting selections (Rainie et al., 2012). According to a report by Pew research center (2012), a good part of the contents that are available in the social network sites are not similar to the individual's perspectives. This means that majority of users in the social network sites (almost 73 percent) disagree with their friends' opinions and feedbacks on the political posts and 38 percent of them are actually surprised of the political opinions and discoveries that are expressed by their contacts.

These results are in line with the recent discussions by the scholars on the impact of the sociality in its high levels and expansive networks on the diversification of the political discussion (Brundidge, 2010b; Kim et al., 2012; Kim et al., 2013). However, the important concern is the extent that the increased exposure to disagreement and differences in the ideology can effect on the users' willingness to express their political opinion in the social media context. Some studies (Kalaboukis et al., 2011; Kim et al., 2013; Wojcieszak et al., 2009) on one hand showed that being exposed to different political discussion may create some deliberation processes in the online mode (Stroud, 2010; Sunstein, 2006). Other studies (Mutz, 2006; Valenzuela et al., 2012) though show a negative correlation between being exposed to disagreements and participation in the political discussion. Similarly, Pew research Centre (2012) has found in a research that majority of users (68 percent) are silent when they read disagreeable political contents that are shared by others and 22 percent of them decide intentionally not to express their opinions on the subject in order not to offend the others ( $p$. 8).

Ultimately social media offer a space where the visibility of the people causes social influence (Kwon et al., 2014). Presence of others can constrain or encourage the individual behavior and communication in SNSs can create a novel type of sociality (Papacharissi et al., 2011) that is a reduced level of anonymity and higher levels of peer to peer monitoring and the online presence can bring intensive networking opportunities with a greater speed with the offline social contacts. However, when social network sites offer more sociality, there are more interpersonal and group influences. One risk is that as a result of the interplay between argumentative sociality and media advantages, there may be an increased social influence on the propagated political ideas and beliefs that undermine the favorable views equally and quickly. In other words, it is possible that a spiral of silence (SOS) process can be caused by the 
political communication that is undergoing in the highly sociable platforms such as social network sites (Noelle-Neumann et al., 1993). In any case, the mechanism that control and affect individual's political opinions in the network exposure has not been fully explored yet.

Mou et al. (2013) also investigated the influence of SNS use and online political discussion in China. They assess the political activities among Chinese net users to understand the influence of social media in this country in the context of political attitudes and political participation. They found out a moderate but positive relationship between online forum and use of social networking sites on online political discussions. It seems that this paper highlights the role of SNSs in political change of the regimes like China that impose censorship on the Internet. To sum up he found following results: social network sites use by Iranian university students have a significant positive effect on their political attitude, and political attitude mediates the positive effect of social network used by Iranian university students on their political behavior.

\section{METHODOLOGY}

This study employed mixed-method design including quantitative and qualitative methods. The quantitative methods employed a correlational design and mediation mechanism to investigate whether there are any relationships between variables including political attitude, and political knowledge and social network sites. In the qualitative phase, interviews were conducted to identify lecturers' opinion about social network in Iran. The research sample is selected randomly from the Iranian university students to collect quantitative data. This study aims to identify whether there is any relationship between social networks and political knowledge and attitudes. Therefore, the mean of inferential statistics examines variation and any probable interrelationships between variables and tests the research hypotheses. The interview was employed to get more in-depth information on using of social network sites by Iranian university students and their political knowledge and attitude.

Three questionnaires were adapted for the purpose of the current study. The first questionnaire is on the social network sites was an adapted version of the questionnaire retrieved from Qualtrics.com (retrieved from https://tltc.qualtrics.com/jfe6/form/SV71 ko5tIrvYsPScYon11.07.2015). The second questionnaire is about the relationship between social network sites and political attitude and behavior was an adapted version of the survey by Rainie et al. (2012). Lastly, the third questionnaire is to collect data on the students' level of political knowledge that was adapted from a PhD Thesis by Sardarnia (2003).

This study employed a 106-item questionnaire which is consisted of three main parts. The first part has eight questions about demographic information including participants' age, gender, education level, university, family members, and location and accessing to the Internet.

The second part was twelve close-ended questions about political knowledge regarding different political parties and official figures in Iran, about the parliament and the political movements of the country. This part ended with questions about political issues of other countries. Part $\mathrm{C}$ with nine questions in the Likert scale asked about the political use of the social network sites and different applications the students prefer to use. Likert-type scale is a psychometric scale that is frequently used in the questionnaires, and it is the most commonly used scale in survey research. By using Likert-type scale, a researcher can identify the level of 
agreement of the respondents to a subject. Part D with 10 questions in the same scale was going to ask about the political attitudes of the students, their trust and interest. Five questions of Part E questions asked about political participation to express personal opinions in the Likert scale, such as writing to politicians or voting in social network sites.

In the first step, the states were selected based on the location of the universities (located in border town, city and downtown). This research was done in three public universities in Tehran, i.e., University of Tehran, Kharazmi University and Shahrood University of Technology. These universities are located in the city, border town and down town, respectively. In the next step, the faculties and department were chosen based on multi stage cluster sampling (Refer to 3.7). In the end, a random sampling method was employed to select the students as respondents. As access to every student was impossible, a small segment of the population was selected because of two main reasons (1) availability of the study resources (finance, time, manpower); and (2) accessibility of universities. As a result, in the second step, three universities were selected within the selected states. A total of 400 participants were finally chosen for responding to questionnaire.

For conducting interview, 12 lecturers who used social networks and were teaching at three different universities across the country were selected randomly, namely from Tehran, Karaj, and the city of Shah rood. These lecturers were then asked to respond to the questionnaire. Due to some problems like difficult face-to-face accessibility to the interviewees, the interview was conducted by the use of an E-mail. After receiving the responses, the researcher began to compare and analyze the data respectively.

The collected data were analyzed using SPSS and Structural Equation Modeling (PLSSEM) approach provided by Smart-PLS. Hair et al. (2009) stated that SEM is an advanced technique for data analysis and it also an extension for other previous multivariate techniques. It is also a general prototype and method for variables analysis and studying their relationship. The SEM process is consisted of two main steps of "validating the measurement model" and "fitting the structural model" (Katz et al., 1974).

In current study, the collected data were analyzed using SPSS and Structural Equation Modeling (PLS-SEM) approach provided by Smart-PLS. Structural equation modeling (SEM) is considered a family of statistic models for explaining the relationship among multiple variables (Hair, 2010). Structural Equation Modeling (SEM) is a second generation multivariate method that provides assessing the reliability and validity of the instrument as well as evaluation of relationship between independent variables and dependent variables compare to multiple regression analysis which is limited only for evaluation of relationship among variables.

\section{Mediator Effect of Political Knowledge and Attitude}

\section{RESULTS AND DISCUSSION}

The results revealed that "political knowledge and political attitude" had mediating effect on dependent variable. 


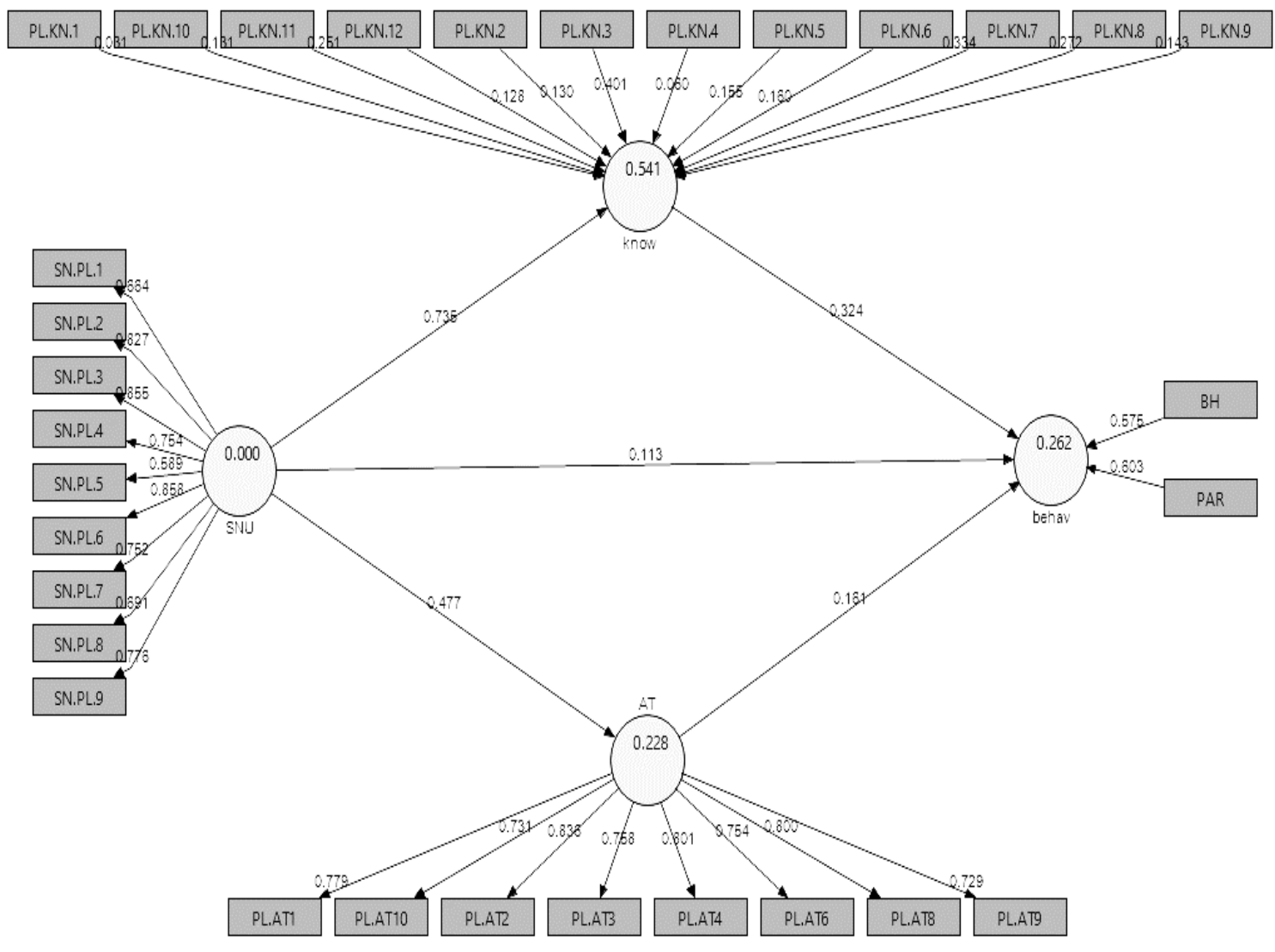

Figure 1: Mediator variables

Result of boot strapping method after introducing mediator variables (political knowledge and political attitude) in the model (Figure 1) showed the effect of social network use on political knowledge $(B=0.0 .738, p<0.05)$ and political attitude $(B=0.0 .266, p<0.05)$ were positive and significant. Political knowledge also influenced positively on political behavior $(B=0.292, p<0.05)$. The effect of political attitude on political behavior was also positive and significant $(B=0.0 .158, p<0.05)$. Political knowledge also influenced positively on political attitude $(B=0.286, p<0.05)$.

The R2 for political knowledge was 0.544 which indicates $54.4 \%$ of Political knowledge can be explained by social network use and the R2 for political attitude was 0.265 which indicates $26.5 \%$ of political attitude can be explained by social network use.

Table 1: Test of the total effects using bootstrapping (with mediators)

\begin{tabular}{lccc}
\hline Variable & R Square & Communality & GOF \\
\hline Knowledge & 0.544 & 0.169 & 0.498 \\
Attitude & 0.265 & 0.600 & 0.346 \\
Social Network Use & & 0.572 & \\
\hline
\end{tabular}




\section{Test of mediation}

Mediation addresses how an independent variable causes a change in a dependent variable. When a third variable is intermediate in the relationship between two variables, it is called a mediator. In simple terms, a mediator is a variable that accounts for all or part of the relationship between a predictor and an outcome. The figure below displays the path diagram for a single mediator model (Figure 2).

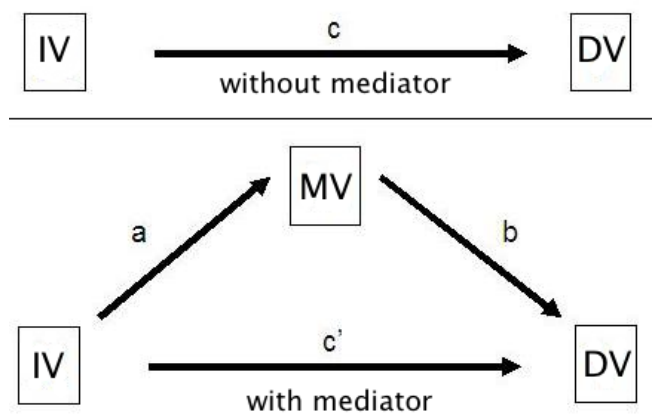

Figure 2: Mediator model

Table 2 represents the mediation test for two possible paths for retention. According to these results the mediation effect of political knowledge and political attitude between both social network use and political behavior were statistically significant. The highest mediation effect belonged to communication.

Table 1: Test of the mediation effects using bootstrapping

\begin{tabular}{cccccc}
\hline Path & ab & SE & z value & p value & VAF \\
\hline SNU -> AT -> BH & 0.042 & 0.020 & 2.093 & 0.037 & $23.6 \%$ \\
SNU -> KN -> BH & 0.215 & 0.057 & 3.764 & $<0.001$ & $61.4 \%$ \\
\hline
\end{tabular}

AT: Attitude, SNU: social network sites uses, KN: Knowledge, BH: behavior, PARTC: participation

Effect Size of 2 and $q 2$

The change in the R2 value when a specified exogenous construct is omitted from the model can be used to evaluate whether the omitted construct has a basic impact on the endogenous constructs. This measure is referred to as the $\mathrm{f} 2$ effect size. The effect size can be calculated as in Figure 3.

$$
f^{2}=\frac{R_{\text {included }}^{2}-R_{\text {excluded }}^{2}}{1-R_{\text {included }}^{2}}
$$

Figure 3: Measurement formula for effect size 
Where $\mathrm{R} 2$ included and $\mathrm{R} 2$ excluded are the $\mathrm{R} 2$ values of the endogenous latent variable when a selected exogenous latent variable is included in or excluded from the model. Guidelines for assessing / 2 are that values of $0.02,0.15$, and 0.35 , respectively, represent small, medium, and large effects (Cohen, 1988) of the exogenous latent variable. According to Table 1.3 the effect size of Knowledge and Social network use on the political behavior are medium effect.

The guideline values for assessment of q2 effect sizes are 0.02 (small), 0.15 (medium), and 0.35 (large) effects of predictive relevance of an exogenous variable. Based on the results social network use had a medium effects of predictive relevance of political behavior while knowledge and attitude had a small effects.

Table 3: Results of effect size $\mathrm{f} 2$ and $\mathrm{q} 2$ for all exogenous variables

\begin{tabular}{lcc}
\hline Predictor & $\mathbf{f 2}$ & $\mathbf{q 2}$ \\
\hline Knowledge & 0.15 & 0.11 \\
Attitude & 0.05 & 0.01 \\
Social network use & 0.019 & 0.016
\end{tabular}

$\mathrm{f}^{2}$ ": the relative impact of an exogenous construct on an endogenous construct, $\mathrm{q} 2$ : the relative predictive relevance of an exogenous construct (predictor) on an endogenous construct

The results obtain from interview, revealed that all participants used social networking services (SNSs). Lecturers and scholars use social networks in their leisure time or even at work and at the university. It was also found that they use almost all major social networking sites including Facebook and Twitter.

In the case of political knowledge of Iranian students, it was found that participants believed that easy access to modern information sources has increases political knowledge of the students. They also claimed that Iranian university students continue to be aware of all national and international events. For the kind of political knowledge of social networking sites which leads to filtering by the government, the lecturers' answers seemed to be almost different with a variety of responses. A few interviewees assert that publishing and disseminating political news against the current establishment of the country may make the government remove or block some social media. They say that such networks could actually help grow political knowledge and awareness among people, which means a menace to the security of the nation for the government. That is why it attempts to prevent its citizens from accessibility to free information through social networking sites. The other finding of the study in the interview section is related to the current status of social network sites in Iran. The participants' answers revealed that over half of them are entirely dissatisfied with the situation of the social networks.

Lecturers and scholars in the current study responded in different ways on whether the access and use of social networking services can improve political knowledge and change the political attitude and behavior of the Iranian youths. They mostly believed that using social networks may affect the political attitude of the Iranian youths. Moreover, they mentioned that inherent features of social media are to affect, change, and shape the attitude and conduct of audience, especially young people everywhere. Also, easy access to social networking sites can 
contribute to the development and the policy of a country. Social media can also promote the national solidarity by bringing people together. It can help young people increase their knowledge about governments and parties in a country by reading and gaining information about them. Therefore, they can judge and have control over them properly in the case of having a real role in their country's fate. Nevertheless, there were four interviewees also who disapproved the idea that social networking services lead to improving the political knowledge and changing the behavior of young people in a country.

One of the main aspects of the social networks in Iranian society is their filtering issue. Most of them are blocked totally or partly by the government. It was found that the majority of the academics explicitly disapproved blocking social networking services except for the websites which are immoral and have detrimental effects on children. They believed that websites should be filtered if they are against moral issues. They also mentioned that in a democratic society, political information should not be considered as categorized information and it is individuals' right to be informed.

The general view therefore was that the filtering of news websites and preventing the society from access to useful information is unreasonable and unacceptable. It makes people of a country fall behind with global issues and trends. As for the effects of blocking the access to social networks on the political knowledge, all the respondents expressed a negative opinion. They believe that filtering or blocking social networking services appears not to be rational, effective, and practical. They also argue that there are always ways to reach these kinds of information. For example, they can flout the rules and employ anti-filtering devices to overcome filtering policies. Finally, in case of alternative suggestions for not filtering social networking services in Iran, scholars and lecturers generally emphasized on the importance of teaching people, raising their awareness of the occurring events, and laying down some rules and regulations and enforcing them in the society. Therefore, enlightening society members on use of the social networks can play a vital role.

In this research, the result of boot strapping method after introducing mediator variables (political knowledge and political attitude) in the model showed the effect of social network use on political knowledge $(B=0.0 .738, p<0.05)$ and political attitude $(B=0.0 .266$, $\mathrm{p}<0.05)$ were positive and significant. Political knowledge also influenced positively on political attitude $(B=0.286, p<0.05)$.

The R2 for political knowledge was 0.544 which indicated $54.4 \%$ of Political knowledge can be explained by social network use and the R2 for political attitude was 0.265 which indicated $26.5 \%$ of political attitude can be explained by social network use.

Based on the results, social network use had a medium effect of predictive relevance of political behavior while knowledge and attitude had a small effect. According to these results the mediation effect of political knowledge and political attitude between both social network use and political behavior were statistically significant. The highest mediation effect belonged to communication. Based on the results social network use had a medium effect of predictive relevance of political behavior while knowledge and attitude had a small effect.

The results of the current study confirm to some extent that civil society in Iran is not developed cohesively so it can hope that the presence of the social networks and their strength can help in developing the infrastructures, creating the culture of networking, increasing the 
public participation and therefore it will lead into higher levels of social capital. These improvements will result in efficiency, reduction of the government engagement in social and business activities, decentralization, correction of incongruous structures and accountability. Indeed, social networks are among the effective elements in cultural reproduction in social, political and organizational sectors. These networks help in shaping the relationships between people and organizations in different domains including the political life in the society. Social networks have effects on the social capital in terms of people relations and invite people to cooperation, coordination and participation. Social networks help in building mutual trust and good intention and they strengthen mental convergence.

The findings of the current study showed that there is generally a direct and positive relation between the level of use of social networks and political knowledge and attitude. The results showed that when there is a moderate level of participation in society, the level of political knowledge and activities are also moderate. Thus, it is probable that in the societies rather than Iran with higher levels of social participation in civil society, people have higher levels of political behavior. However, social networks are an important anticipator for the political participation as it seems that such networks are prerequisites for civil culture and stable democracy. In other words, social participation is a part of stable cultural life which helps the democracy to survive.

\section{CONCLUSION}

This study investigates the role of social networks on political knowledge and political attitudes of Iranian university students. The results of boot strapping method in structural equation modeling revealed that mediator variables (political knowledge and political attitude) in the model showed the effect of social network use on political knowledge $(B=0.0 .738, p<0.05)$ and political attitude $(B=0.0 .266, p<0.05)$ were positive and significant. The effect of political attitude on political behavior was also positive and significant $(B=0.0 .158, p<0.05)$. Political knowledge also influenced positively on political attitude $(B=0.286, p<0.05)$. Moreover, political knowledge can be explained by social network use and the political attitude can also be explained by social network use.

Based on the results social network use had a medium effects of predictive relevance of political behavior while knowledge and attitude had a small effect. According to these results the mediation effect of political knowledge and political attitude between both social network use and political behavior were statistically significant. The highest mediation effect belonged to communication. Based on the results, social network use had a medium effects of predictive relevance of political behavior while knowledge and attitude had a small effect.

As a result, the finding revealed the following outcomes: Social network sites use by Iranian university students have a significant positive effect on their political knowledge and political knowledge mediates the positive effect of social network use by Iranian university students on their political behavior. The results for the research objectives also revealed that the political attitude of the Iranian university students have significant positive effects on their political knowledge and attitude. It was also showed that political knowledge plays a mediating role in the political behavior of the students in the current study. 
The results also confirm the views on the necessity of deploying an intelligent filtering mechanism rather than indiscriminate blocking of the social network websites. Government can include social networks in the websites and portals in order to disseminate information on their agenda and decisions to build a stable public stand in the society. Such an opportunity will increase the mutual understanding and relationship between the decision makers and the public. According to the results of the current study, political parties in Iran have little impact on the social network users, thus based on the findings it can be suggested that the political parties use such emerging potential to increase the political participation of Iranian students. In the practical implication, it is suggested that different Iranian ministries and government agencies take part actively in the communication channels using social network sites in order to interact with the public. This will help them to inform the public about their work and progresses and they can receive and analyze the feedback from different social sectors and change their services to the benefit of both public and the government.

\section{BIODATA}

Abdolreza Alami is a PhD student at Department of Media Studies, Universiti Malaya. Email: abdolrezaalami@gmail.com

Hamedi Mohd Adnan is an Associate Professor at the Department of Media Studies, Universiti Malaya. Email: hamedi@um.edu.my

Sedigheh Shakib Kotamjani is a lecturer, Department of Teaching English as Second Language and Faculty of Educational Studies, Universiti Putra Malaysia. Email: sedigheh@upm.edu.my 


\section{REFRENCES}

Baumgartner, J. C., \& Morris, J. S. (2010). MyFaceTube politics social networking web sites and political engagement of young adults. Social Science Computer Review, 28(1), 24-44. doi: 10.1177/0894439309334325

Beilin, J., Blake, M., Cowell, M., Fisher, D., Gilbert, S., Hanson, R., \& Woodworth, S. (2009). Iranian election on Twitter: The first eighteen days. Web Ecology Project. Retrieved from http://www.webecologyproject.org/2009/06/iran-election-on-twitter/

Brundidge, J. (2010a). Encountering "difference" in the contemporary public sphere: The contribution of the Internet to the heterogeneity of political discussion networks. Journal of Communication, 60(4), 680-700.

Brundidge, J. (2010b). Political discussion and news use in the contemporary public sphere: The "accessibility" and "traversability" of the Internet. Javnost-the Public, 17(2), 63-81.

Calhoun, C. (1988). Populist politics, communications media and large scale societal integration. Sociological Theory, 219-241.

Cheung, C. M., Chiu, P.-Y., \& Lee, M. K. (2011). Online social networks: Why do students use Facebook?. Computers in Human Behavior, 27(4), 1337-1343.

Dimitrova, D. V., Shehata, A., Strömbäck, J., \& Nord, L. W. (2011). The effects of digital media on political knowledge and participation in election campaigns: Evidence from panel data. Communication Research, 0093650211426004.

Downey, J., \& Fenton, N. (2003). New media, counter publicity and the public sphere. New Media \& Society, 5(2), 185-202.

Fabrigar, L. R., Petty, R. E., Smith, S. M., \& Crites Jr, S. L. (2006). Understanding knowledge effects on attitude-behavior consistency: The role of relevance, complexity, and amount of knowledge. Journal of Personality and Social Psychology, 90(4), 556.

Gajora, L. (2011b). Effects of Internet use on actual and self-perceived political knowledge, issue certainty and political participation (Thesis, Wake Forest University, Winston-Salem, NC). Retrieved from https://wakespace.lib.wfu.edu/handle/10339/33436

Hair, J. F. (2010). Multivariate data analysis. New York: Pearson College Division.

Hair, J. F., Black, W. C., Babin, B. J., \& RolphE, A. (2006). Multivariate data analysis. New Jersey: Prentice Hall.

Hair, M., \& Tripp, C. (1995). Alkylchlorosilane reactions at the silica surface. Colloids and Surfaces A: Physicochemical and Engineering Aspects, 105(1), 95-103.

Hanson, G., Haridakis, P. M., Cunningham, A. W., Sharma, R., \& Ponder, J. D. (2010). The 2008 presidential campaign: Political cynicism in the age of Facebook, MySpace, and YouTube. Mass Communication and Society, 13(5), 584-607.

Huckfeldt, R. R., \& Sprague, J. (1995). Citizens, politics and social communication: Information and influence in an election campaign. Cambridge: Cambridge University Press.

Kalaboukis, C., \& Kim, E.-G. (2011). Sharing of content and hop distance over a social network. New York: Google Patents.

Katz, E., Blumler, J., \& Gurevitch, M. (1974). The use of mass communication. Beverly Hills: California: Sage. 
Kenski, K., \& Stroud, N. J. (2006). Connections between Internet use and political efficacy, knowledge, and participation. Journal of Broadcasting \& Electronic Media, 50(2), 173192.

Kim, M., \& Park, H. W. (2012). Measuring Twitter-based political participation and deliberation in the South Korean context by using social network and Triple Helix indicators. Scientometrics, 90(1), 121-140.

Kim, Y., Hsu, S. H., \& de Zúñiga, H. G. (2013). Influence of social media use on discussion network heterogeneity and civic engagement: The moderating role of personality traits. Journal of Communication, 63(3), 498-516.

Kim, Y., Sohn, D., \& Choi, S. M. (2011). Cultural difference in motivations for using social network sites: A comparative study of American and Korean college students. Computers in Human Behavior, 27(1), 365-372. doi: 10.1016/j.chb.2010.08.015

Kwon, K. H., Moon, S.-I., \& Stefanone, M. A. (2015). Unspeaking on Facebook? Testing network effects on self-censorship of political expressions in social network sites. Quality \& Quantity, 49(4), 1417-1435.

Kwon, K. H., Stefanone, M. A., \& Barnett, G. A. (2014). Social network influence on online behavioral choices exploring group formation on social network sites. American Behavioral Scientist, 58(10), 1345-1360.

Mcleod, J. M., Scheufele, D. A., \& Moy, P. (1999a). Community, communication, and participation: The role of mass media and interpersonal discussion in local political participation. Political Communication, 16(3), 315-336.

McLeod, J. M., Scheufele, D. A., Moy, P., Horowitz, E. M., Holbert, R. L., Zhang, W. W., . . . Zubric, J. (1999b). Understanding deliberation - The effects of discussion networks on participation in a public forum. Communication Research, 26(6), 743-774. doi: 10.1177/009365099026006005

Mou, Y., Atkin, D., Fu, H., Lin, C. A., \& Lau, T. (2013). The influence of online forum and SNS use on online political discussion in China: Assessing "spirals of trust". Telematics and Informatics, 30(4), 359-369.

Noelle-Neumann, E., \& Noelle-Neumann, E. (1993). The spiral of silence: Public opinion, our social skin. Chicago: University of Chicago Press Chicago.

Papacharissi, Z., \& Mendelson, A. (2011). 12 Toward a new (er) sociability: uses, gratifications and social capital on Facebook. New York: Routledge.

Rainie, L., \& Smith, A. (2012, June 12). Social networking sites and politics. Washington, DC: Pew Internet \& American Life Project.

Richey, S. (2008). The autoregressive influence of social network political knowledge on voting behaviour. British Journal of Political Science, 38, 527-542. doi: 10.1017/s0007123408000264

Shah, D. V., Cho, J., Nah, S., Gotlieb, M. R., Hwang, H., Lee, N. J., . . . McLeod, D. M. (2007). Campaign ads, online messaging, and participation: Extending the communication mediation model. Journal of Communication, 57(4), 676. doi: 10.1111/j.14602466.2007.00363.x 
Examining the Impact of Using of Social Networks on Political Knowledge and Political Attitude by Iranian University Students

Abdolreza Alami, Hamedi Mohd Adnan \& Sedigheh Shakib Kotamjani

Shah, D. V., Kwak, N., \& Holbert, R. L. (2001). "Connecting" and "disconnecting" with civic life: Patterns of Internet use and the production of social capital. Political Communication, 18(2), 141-162. doi: 10.1080/105846001750322952

Smith, A. W., \& Rainie, H. (2008). The Internet and the 2008 election. New York: Pew Internet \& American Life Project.

Smock, A. D., Ellison, N. B., Lampe, C., \& Wohn, D. Y. (2011). Facebook as a toolkit: A uses and gratification approach to unbundling feature use. Computers in Human Behavior, 27(6), 2322-2329.

Sotirovic, M., \& McLeod, J. M. (2001). Values, communication behavior, and political participation. Political Communication, 18(3), 273-300. doi: 10.1080/10584600152400347

Sweetser, K. D., \& Kaid, L. L. (2008a). Stealth soapboxes: Political information efficacy, cynicism and uses of celebrity weblogs among readers. New Media \& Society, 10(1), 67-91.

Sweetser, K. D., \& Lariscy, R. W. (2008b). Candidates make good friends: An analysis of candidates' uses of Facebook. International Journal of Strategic Communication, 2(3), $175-198$.

Sweetser, K. D., \& Lee Kaid, L. (2008c). Stealth soapboxes: Political information efficacy, cynicism and uses of celebrity weblogs among readers. New Media \& Society, 10(1), 6791.

Valenzuela, S., Arriagada, A., \& Scherman, A. (2012). The social media basis of youth protest behavior: The case of Chile. Journal of Communication, 62(2), 299-314.

Valenzuela, S., Park, N., \& Kee, K. F. (2009a). Is there social capital in a social network site?: Facebook use and college students' life satisfaction, trust, and participation. Journal of Computer-Mediated Communication, 14(4), 875-901. doi: 10.1111/j.10836101.2009.01474.x

Valenzuela, S., Park, N., \& Kee, K. F. (2009b). Is there social capital in a social network site?: Facebook use and college students' life satisfaction, trust, and participation1. Journal of Computer-Mediated Communication, 14(4), 875-901.

Vitak, J., Zube, P., Smock, A., Carr, C. T., Ellison, N., \& Lampe, C. (2011). It's complicated: Facebook users' political participation in the 2008 election. CyberPsychology, Behavior, and Social Networking, 14(3), 107-114.

Wojcieszak, M. E., \& Mutz, D. C. (2009). Online groups and political discourse: Do online discussion spaces facilitate exposure to political disagreement?. Journal of Communication, 59(1), 40-56.

Zhang, W., Seltzer, T., \& Bichard, S. L. (2013). Two sides of the coin assessing the influence of social network site use during the 2012 US presidential campaign. Social Science Computer Review, 31(5), 542-551.

Zhang, W. W., Johnson, T. J., Seltzer, T., \& Bichard, S. L. (2010). The revolution will be networked the influence of social networking sites on political attitudes and behavior. Social Science Computer Review, 28(1), 75-92. doi: 10.1177/0894439309335162

Zúñiga, H., Molyneux, L., \& Zheng, P. (2014). Social media, political expression, and political participation: Panel analysis of lagged and concurrent relationships. Journal of Communication, 64(4), 612-634. 